\title{
The antidiabetic and protective effects of the methanolic leaf extract of $A$. borneensis in alloxan-induced diabetic rats
}

\author{
Amal Hazirah Matusin ${ }^{1}$, May Poh Yik Goh ${ }^{1}$, Norhayati Ahmad ${ }^{1,2^{*}}$ \\ 1 Environmental and Life Sciences, Faculty of Science, Universiti Brunei Darussalam, Jalan Tungku Link, Gadong, Brunei Darussalam \\ 2 Institute for Biodiversity and Environmental Research, Universiti Brunei Darussalam, Jalan Tungku Link, Gadong, Brunei Darussalam
}

\begin{abstract}
Aidia borneensis or locally known as "sambah bagangan" is consumed as herbal tea in Brunei Darussalam and has been claimed to provide several health benefits. Our study was conducted to determine antidiabetic and protective effects of the methanolic extracts of $A$. borneensis followed by a histopathological evaluation of the pancreatic islets regeneration in response to the treatments. The study was conducted on male Wistar rats, aged 8-10 weeks where diabetes was induced via a single intraperitoneal injection of alloxan at 120 $\mathrm{mg} / \mathrm{kg}$ body weight (b.w.). The rats were then treated with a low dose (LD) of $250 \mathrm{mg} / \mathrm{kg} \mathrm{b}$.w. or a high dose (HD) of $500 \mathrm{mg} / \mathrm{kg}$ b.w. of the A. borneensis extract pre- or post-alloxan administration followed by evaluation of blood glucose levels and histological evaluation of the pancreatic islets over a 12-week experimental period. The intraperitoneal glucose tolerance test for the treated animals was also carried out. Our results report a significant reduction in the blood glucose concentration and increase in ratio of islets to tissue size observed in diabetic rats from both low dose and high dose treated groups compared to the control animals $(p<0.05)$. Improvement of islet morphology was evident in the treated animals. Similar patterns of increased islet to tissue size ratios were also observed in the protective group which received pre-treatment of the extracts prior to diabetes induction. Overall, the present study shows that methanolic extract of the A. borneensis leaf exhibited apparent antidiabetic and protective effects on alloxan-induced diabetic rats.
\end{abstract}

\section{Keywords:}

Aidia borneensis, Pancreas, Islet regeneration, Beta cells, Diabetes

\section{INTRODUCTION}

Throughout the years, the search for medicinal plants with potent activity against chronic diseases has grown in demand due to several reasons such as availability and the increased appreciation for medicinal plants. This is also largely due to the perception of plants being safer alternatives with minimal side effects compared to conventional medicines, although toxicity testing is still necessary to validate the safe use of the plant products ${ }^{1}$. The advantage of medicinal plants has led to the incorporation of numerous plant products into various aspects of modern medicine. According to previous reports, about $25 \%$ of modern drugs available in the market are directly or indirectly derived from plants or natural products ${ }^{1}$.

Rahman et al. (2006) have identified various indigenous plants and functional foods from Brunei Darussalam that are believed to treat diseases based on ethnobotanical knowledge ${ }^{2}$. A. borneensis belongs to the Aidia genus of the Rubiaceae family and is endemic to Borneo. In Brunei Darussalam, A. borneensis is locally known as 'sambal', 'sambar' or 'sambah bagangan'. Traditional folk remedies using A. borneensis have been passed down through generations and the plant is still commonly consumed in Brunei as a herbal tea. Local villagers revealed that the plant possesses beneficial health properties, one of which was for the treatment

*Corresponding author:

*Norhayati Ahmad norhayati.ahmad@ubd.edu.bn 
of gastric pain ${ }^{3}$. Some locals also suggested that $A$. borneensis leaf may be effective for the reduction of glucose levels in diabetic individuals ${ }^{4}$.

There have been some reports based on studies conducted on A. borneensis although limited. However, Awang-Jamil et al. (2019) and Metussin et al. (2017) have reported promising antioxidative and antimicrobial activities for the methanolic and aqueous extracts of the A. borneensis leaves ${ }^{5-6}$. Furthermore, phytochemical screening of the methanolic and aqueous extracts of $A$. borneensis leaves revealed the presence of several flavonoids and phenolic compounds including quinic acid, coumaran, catechol, palmitic acid and other compounds $^{5,7}$. The authors reported that quinic acid (1,3,4,5-tetrahydroxycyclohexane carboxylic acid), a polyphenol-rich antioxidant compound, was the major constituent (38.94\%) in the methanolic leaf extract of A. borneensis. Other than antioxidative properties, Arya and co-workers (2014) found that quinic acid also possesses potent antidiabetic activity when tested on a streptozocin-induced diabetic rat model, whereby its potency was shown to be higher compared to a well-known antidiabetic compound, quercetin ${ }^{8}$. In view of the high composition of quinic acid in A. borneensis which has displayed potent antidiabetic activity, our study was conducted to determine the antidiabetic effects of $A$. borneensis in alloxan induced diabetic rats followed by a histopathological evaluation of the pancreatic islets.

\section{MATERIALS AND METHODS}

\subsection{Plant material collection}

The leaves from A. borneensis were collected from Tutong District, Brunei Darussalam. Species identification was confirmed by taxonomist from Environmental and Life Sciences, Faculty of Science, Universiti Brunei Darussalam. A voucher specimen of the plant was prepared and deposited in the Universiti Brunei Darussalam Herbarium (Voucher number: UBDH/ S/01244).

\subsection{Preparation of extract}

The A. borneensis leaves were shade dried for 2 to 3 weeks and coarsely grinded prior to solvent extraction. The pulverised sample was extracted in methanol (Merck, Germany) using a Soxhlet extraction apparatus. The extract was then dried at $60^{\circ} \mathrm{C}$ using a rotary evaporator to remove the methanol solvent and yield the crude extract in a semi-solid phase. The dried extract was stored in the refrigerator until use.

The extract was prepared for administration into the rats by first dissolving the crude extract in a small amount of methanol before an initial dilution to a concentration of $100 \mathrm{mg} / \mathrm{ml}$ with $0.9 \%$ saline. The extract solution was further diluted to 250 and 500 $\mathrm{mg} / \mathrm{kg}$ body weight (b.w.) for administration into the rats as the low-dose (LD) and high-dose (HD) respecttively. The doses of 250 and $500 \mathrm{mg} / \mathrm{kg}$ body weight (b.w.) was selected based on previous studies in our laboratory. The extracts did not cause any toxic effects to the animals in the administered doses.

\subsection{Antidiabetic activity}

\subsubsection{Ethical statement}

The animal work in the current study has been approved by the University Research Ethics Committee of Universiti Brunei Darussalam (approval reference: UBD/FOS/M2). Procedures are carried out in accordance to the guidelines set out by Universiti Brunei Darussalam as well as internationally accepted guidelines on the care and use of animals for research. Every effort is taken to ameliorate harm to the animals via careful monitoring for signs of pain and distress in accordance to the Universiti Brunei Darussalam guidelines on care and use of animals for research.

\subsubsection{Animals}

Male Wistar rats of age 8-10 weeks (weighing 180-250 g) were obtained from the Universiti Brunei Darussalam animal facility. The animals were housed in cages lined with bedding comprised of wood shavings and kept under normal laboratory conditions with 12 hour light-dark cycle and temperatures of $25 \pm 2^{\circ} \mathrm{C}$. The rats were fed with a standard pellet rat diet (Specialty Feeds, Western Australia) and water ad libitum. Upon completion of the experiments, animals were euthanized with carbon dioxide asphyxiation.

\subsubsection{Experimental design}

Animals were randomly allocated into four main groups where the numbers of animals (n) used in this study were based on our previous studies. The extracts were delivered into each rat via oral gavage at the same time of day for a period of 12 weeks.

The animals were grouped as follows:

(1) Non-diabetic control $(\mathrm{n}=6)$

(2) Alloxan-only treated control $(\mathrm{n}=6)$ : animals treated with alloxan at $120 \mathrm{mg} / \mathrm{kg}$ b.w.

(3) Treatment groups: rats administered with $A$. borneensis extract three times weekly over a period of 12 weeks post-diabetes induction with $120 \mathrm{mg} / \mathrm{kg}$ b.w. of alloxan. The rats were further divided into two separate groups as follows:

(i) Diabetic rats administered with A. borneensis extract at $250 \mathrm{mg} / \mathrm{kg}$ b.w. $(\mathrm{n}=6)$ for a period of 12 weeks following alloxan induction; 
(ii) Diabetic rats administered with A. borneensis extract at $500 \mathrm{mg} / \mathrm{kg}$ b.w. $(\mathrm{n}=6)$ for a period of 12 weeks duration following alloxan induction

(4) Protective group: Animals were pre-treated with either $250 \mathrm{mg} / \mathrm{kg}$ b.w. $(\mathrm{n}=5)$ of the extract or 500 $\mathrm{mg} / \mathrm{kg}$ b.w. $(\mathrm{n}=5)$ of the A. borneensis extract three times weekly for a period of 5 weeks prior to a single alloxan injection of $120 \mathrm{mg} / \mathrm{kg}$ b.w.

\subsubsection{Induction of diabetes}

Diabetes was induced in overnight fasted rats via a single intraperitoneal injection of alloxan monohydrate (Sigma Aldrich, United Kingdom) dissolved in $0.9 \%$ saline at a dose of $120 \mathrm{mg} / \mathrm{kg}$ b.w. Three days following alloxan administration, blood was collected from the animals at the tip of their tail veins and analyzed using a single touch strip whereby the blood glucose readings were measured in $\mathrm{mmol} / \mathrm{L}$. Animals with a postprandial blood glucose reading of more than $20.0 \mathrm{mmol} / \mathrm{L}$ were selected and used in the study. Blood glucose levels and the body weights of the animals were monitored at weeks 4,8 and 12 of the experimental period.

For animals in the protective group that received pre-treatment with A. borneensis extract, the blood glucose reading was recorded at 72 hours following alloxan administration. Animals were considered diabetic when blood glucose reading exceeded 11.1 $\mathrm{mmol} / \mathrm{L}(200 \mathrm{mg} / \mathrm{dL})^{10}$.

\subsubsection{Intraperitoneal glucose tolerance test (IPGTT)}

Animals were fasted overnight prior to carrying out IPGTT at the end of the experimental period. Animals were administered with glucose at $2 \mathrm{~g} / \mathrm{kg}$ b.w. via intraperitoneal injection and blood glucose readings were recorded at 15, 30, 60, 90 and 120 minutes following glucose administration. All blood glucose readings were measured using a single touch glucometer (Style Free Optium, Abbot Diabetes Care Ltd.).

\subsubsection{Histological analysis of pancreatic islet}

Animals ( $\mathrm{n}=3$ ) from each group were euthanized at weeks 4,8 and 12 via carbon dioxide asphyxiation for histological analysis. The pancreatic tissues were harvested and fixed in 3.7\% formaldehyde solution for 48 hours, followed by tissue dehydration. The dehydrated tissues were embedded in paraffin wax. Samples of the paraffin-embedded pancreas tissues were sectioned at a random initial point using a microtome to obtain sections of $10 \mu \mathrm{m}$ thickness. Samples were collected at every 50 section intervals after the starting point. Two sampled sections per pancreas tissue block were selected for staining with haematoxylin. Microscopic images of the stained tissues were observed with a light microscope (Olympus) connected to the CellSens software for live viewing of the tissues.

\subsubsection{Determination of ratio of islet to tissue area}

The determination of ratio of islet to tissue area was carried out as previously described ${ }^{9}$. Image J software version 1.50s (National Institute of Health) was used to measure the islet size area relative to the area of the whole pancreas. The ratios were determined by dividing the total islet area $\left(\mu \mathrm{m}^{2}\right)$ with the total area of the whole pancreatic tissue section $\left(\mu \mathrm{m}^{2}\right)$ of each individual animal.

\subsection{Statistical Analysis}

The data was represented as mean \pm SEM and analyzed using a Graph Pad Prism Software (Windows Version 6.01, Graphpad Software, Inc). Two-way ANOVA analysis were carried out to determine statistical differences among the groups, followed by post-hoc Dunnett's and Sidak's multiple comparisons tests. Significant difference was indicated by $p<0.05$.

\section{RESULTS}

\subsection{Effect of A. borneensis leaf extract on blood glucose}

Both 250 and $500 \mathrm{mg} / \mathrm{kg}$ b.w. dosages of the $A$. borneensis extract resulted in a significant decrease $(p<0.05)$ in blood glucose concentration in alloxaninduced animals, whereby the effect between two dose groups were comparable (Table 1). Animals in the protective group that received pre-treatment with the extract was also protected against hyperglycaemia and islet damage. The protective effect was more prominent in the group that received a higher dose of the extract, with blood glucose concentration maintained at normal levels in the animals.

The IPGTT data shows that animals in both low and high dose treatment groups had reduced blood glucose concentration following intraperitoneal glucose administration in the fasted animals (Figure 1). In comparison, the IPGTT blood glucose readings of the animals in the protective groups were higher than those of the treatment groups within the first 30 minutes of intraperitoneal glucose administration, especially for animals that received pre-treatment with the high-dose of the A. borneensis extract at 15 minutes post-blood glucose spike. From 30 minutes onwards, the animals in the high dose-treated protective group gradually showed a progressive decline in their blood glucose levels eventually reaching blood glucose levels similar to those in the normal untreated and treatment groups at 120 minutes post-intraperitoneal glucose administration. 
Table 1. Blood glucose concentration of animals treated with A. borneensis methanolic leaf extract.

\begin{tabular}{|c|c|c|c|c|}
\hline \multirow[b]{2}{*}{ Time } & \multicolumn{4}{|c|}{ Blood glucose concentration $(\mathrm{mmol} / \mathrm{L})$} \\
\hline & 72 hours & 4 weeks & 8 weeks & 12 weeks \\
\hline Normal control & $6.10 \pm 0.35$ & $3.77 \pm 0.11$ & $4.82 \pm 0.15$ & $4.38 \pm 0.16$ \\
\hline Alloxan only & $27.10 \pm 0.50$ & $24.60 \pm 3.03$ & $25.75 \pm 1.15$ & $27.63 \pm 0.17$ \\
\hline $\begin{array}{l}\text { Alloxan + A. borneensis } \\
250 \mathrm{mg} / \mathrm{kg} \text { b.w. }\end{array}$ & $27.90 \pm 0.00$ & $17.47 \pm 4.24^{\mathrm{a}}$ & $12.40 \pm 3.10^{\mathrm{a}}$ & $9.20 \pm 2.48^{\mathbf{a}, \mathbf{b}}$ \\
\hline $\begin{array}{l}\text { Alloxan + A. borneensis } \\
500 \mathrm{mg} / \mathrm{kg} \text { b.w. }\end{array}$ & $27.90 \pm 0.00$ & $14.30 \pm 3.83^{\mathrm{a}}$ & $10.20 \pm 2.16^{\mathrm{a}}$ & $8.50 \pm 0.60^{\mathbf{a}, \mathbf{b}}$ \\
\hline $\begin{array}{l}\text { A. borneensis } \\
250 \mathrm{mg} / \mathrm{kg} \text { b.w. + Alloxan }\end{array}$ & $14.70 \pm 3.38^{\mathbf{b}}$ & - & - & - \\
\hline $\begin{array}{l}\text { A. borneensis } \\
500 \mathrm{mg} / \mathrm{kg} \text { b.w. + Alloxan }\end{array}$ & $8.58 \pm 2.02^{\mathbf{b}}$ & - & - & - \\
\hline
\end{tabular}

Data represent mean \pm SEM of blood glucose concentration in the normal control $(\mathrm{n}=6)$, alloxan-only control $(\mathrm{n}=6)$, A. borneensis treatment $(\mathrm{n}=6)$ and $A$. borneensis protective groups $(\mathrm{n}=5)$.

a: $p<0.05$ indicates a significant difference with the blood glucose levels measured at 72 hours.

b: $p<0.05$ indicates a significant difference between the extract treated group and alloxan-only control group.

Table 2. Ratio of islet area relative to whole tissue area $\left(\times 10^{-3}\right)$.

\begin{tabular}{|c|c|c|c|c|c|c|}
\hline Time & Normal Control & $\begin{array}{l}\text { Alloxan Only } \\
\text { Control }\end{array}$ & $\begin{array}{c}\text { Alloxan + } \\
\text { A. borneensis } \\
250 \text { mg/kg b.w. }\end{array}$ & $\begin{array}{c}\text { Alloxan + } \\
\text { A. borneensis } \\
500 \text { mg/kg b.w. }\end{array}$ & $\begin{array}{l}\text { A. borneensis } \\
250 \text { mg/kg b.w. } \\
\text { + Alloxan }\end{array}$ & $\begin{array}{c}\text { A. borneensis } \\
500 \mathrm{mg} / \mathrm{kg} \text { b.w. } \\
\text { + Alloxan }\end{array}$ \\
\hline 72 hours & - & $1.83 \pm 0.53$ & $1.83 \pm 0.53$ & $1.83 \pm 0.53$ & $2.58 \pm 0.49^{\mathrm{b}}$ & $3.40 \pm 0.16^{\mathrm{b}}$ \\
\hline 4 weeks & $4.86 \pm 0.35$ & $2.07 \pm 0.20$ & $4.17 \pm 0.90^{\mathrm{a}, \mathrm{b}}$ & $5.04 \pm 0.68^{\mathrm{a}, \mathrm{b}}$ & - & - \\
\hline 8 weeks & $6.14 \pm 1.31$ & $2.13 \pm 0.54$ & $5.41 \pm 0.27^{\mathrm{a}, \mathrm{b}}$ & $6.72 \pm 0.60^{\mathrm{a}, \mathrm{b}}$ & - & - \\
\hline 12 weeks & $6.44 \pm 0.31$ & $2.27 \pm 0.49$ & $6.16 \pm 0.16^{\mathrm{a}, \mathrm{b}}$ & $6.17 \pm 0.55^{\mathrm{a}, \mathrm{b}}$ & - & - \\
\hline
\end{tabular}

The data are represented as mean \pm SEM. All measurements were obtained from 2 pancreatic tissue sections of each animal in the group $(\mathrm{n}=3$ per group). The 72 hours group represent the control for all animals injected with alloxan.

a: $p<0.05$ indicates significant difference with the 72 hours post alloxan treatment group.

b: $p<0.05$ indicates significant difference with the alloxan-only control group within the same time point.

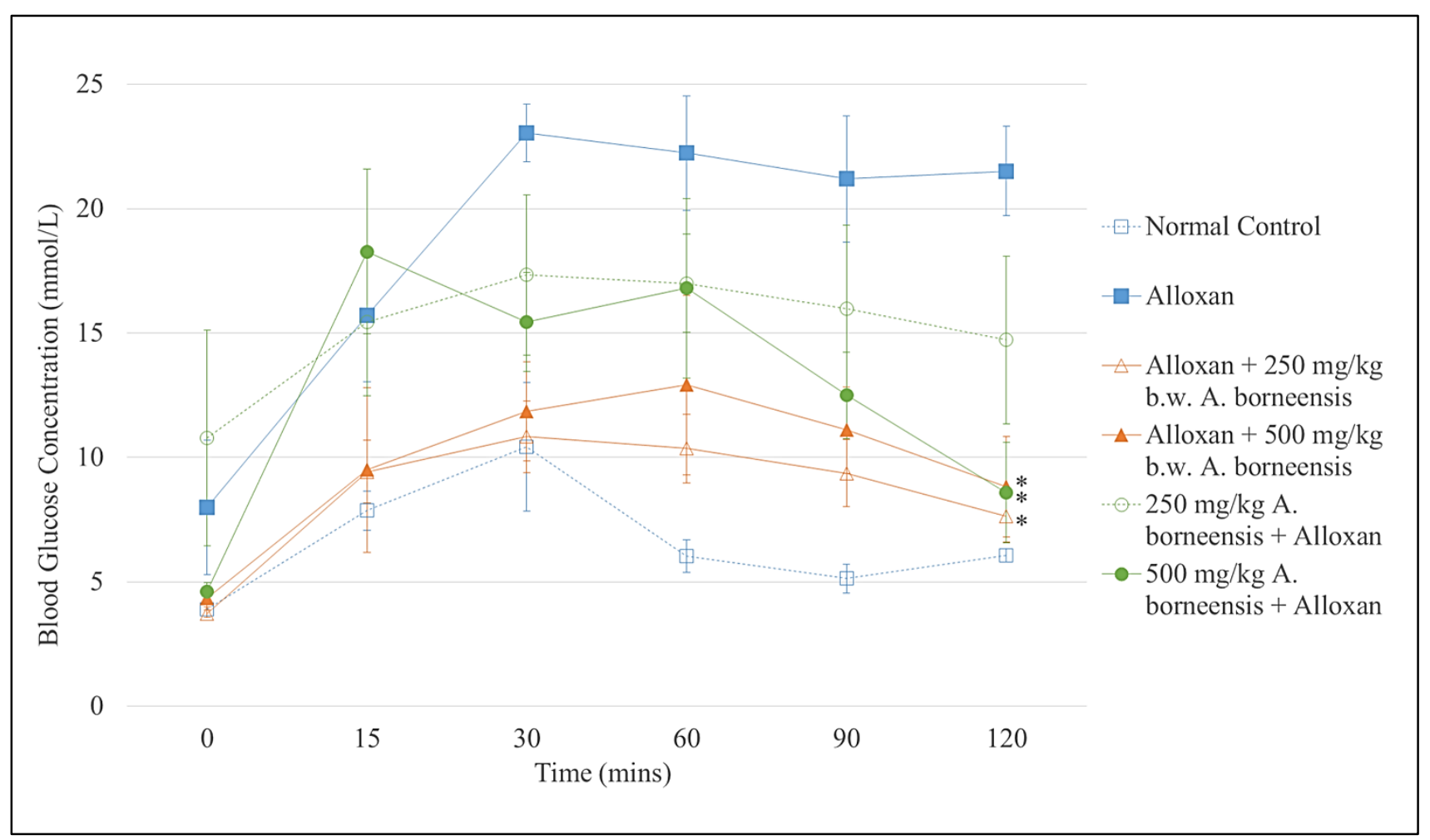

Figure 1. The IPGTT blood glucose concentrations of the experimental rats. Data represent mean \pm SEM of blood glucose concentration in normal control $(\mathrm{n}=6)$, alloxan-only control $(\mathrm{n}=6)$, A. borneensis treatment $(\mathrm{n}=6)$ and A. borneensis protective groups $(\mathrm{n}=5)$.

${ }^{*} p<0.05$ indicates a significant difference between the treatment and protective groups and alloxan only control group at 120 minutes. 


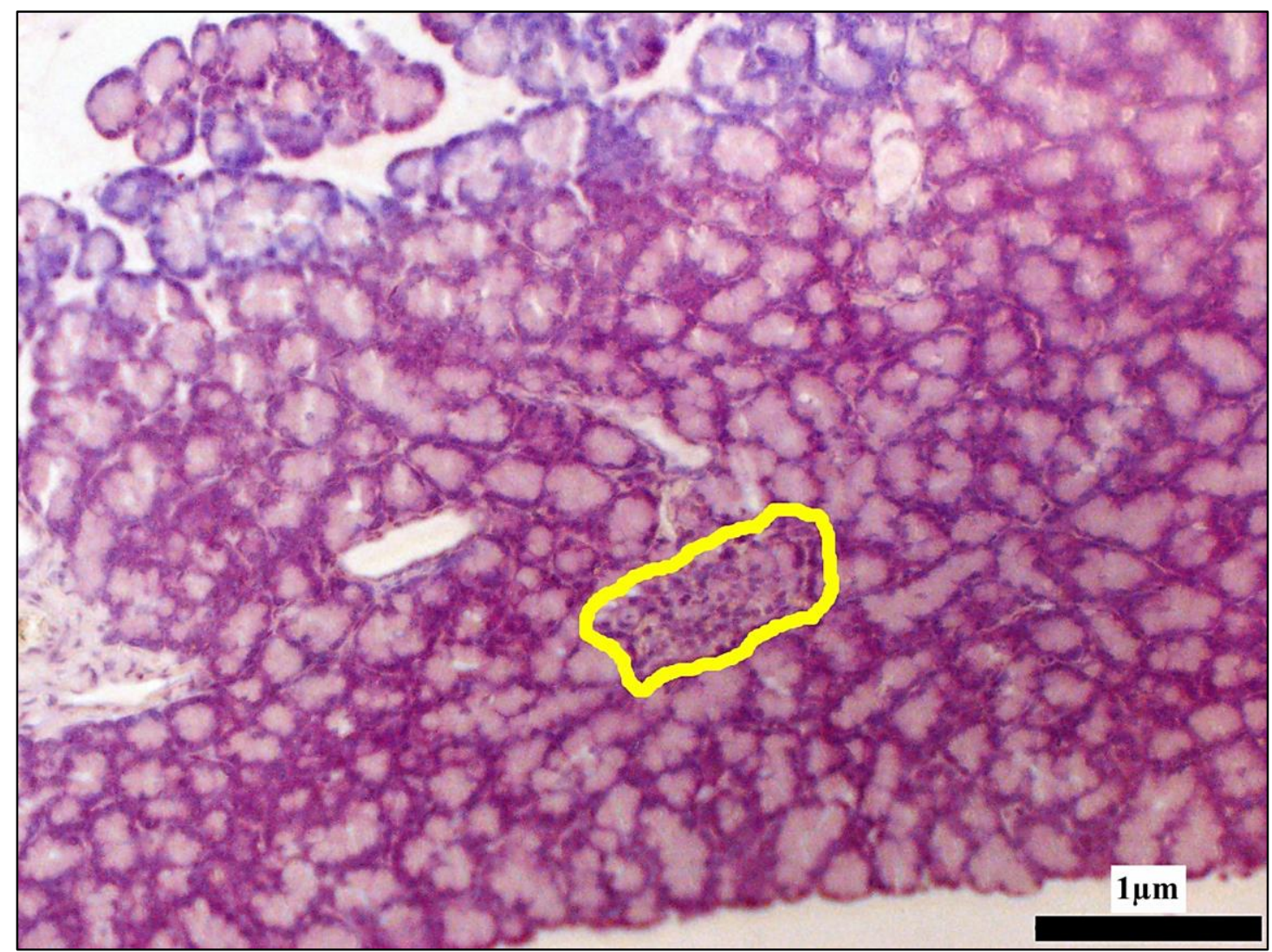

Figure 2. Islet morphology of rat pancreas 72 hours post-alloxan treatment. The pancreatic islet is outlined in yellow (magnification 200x).

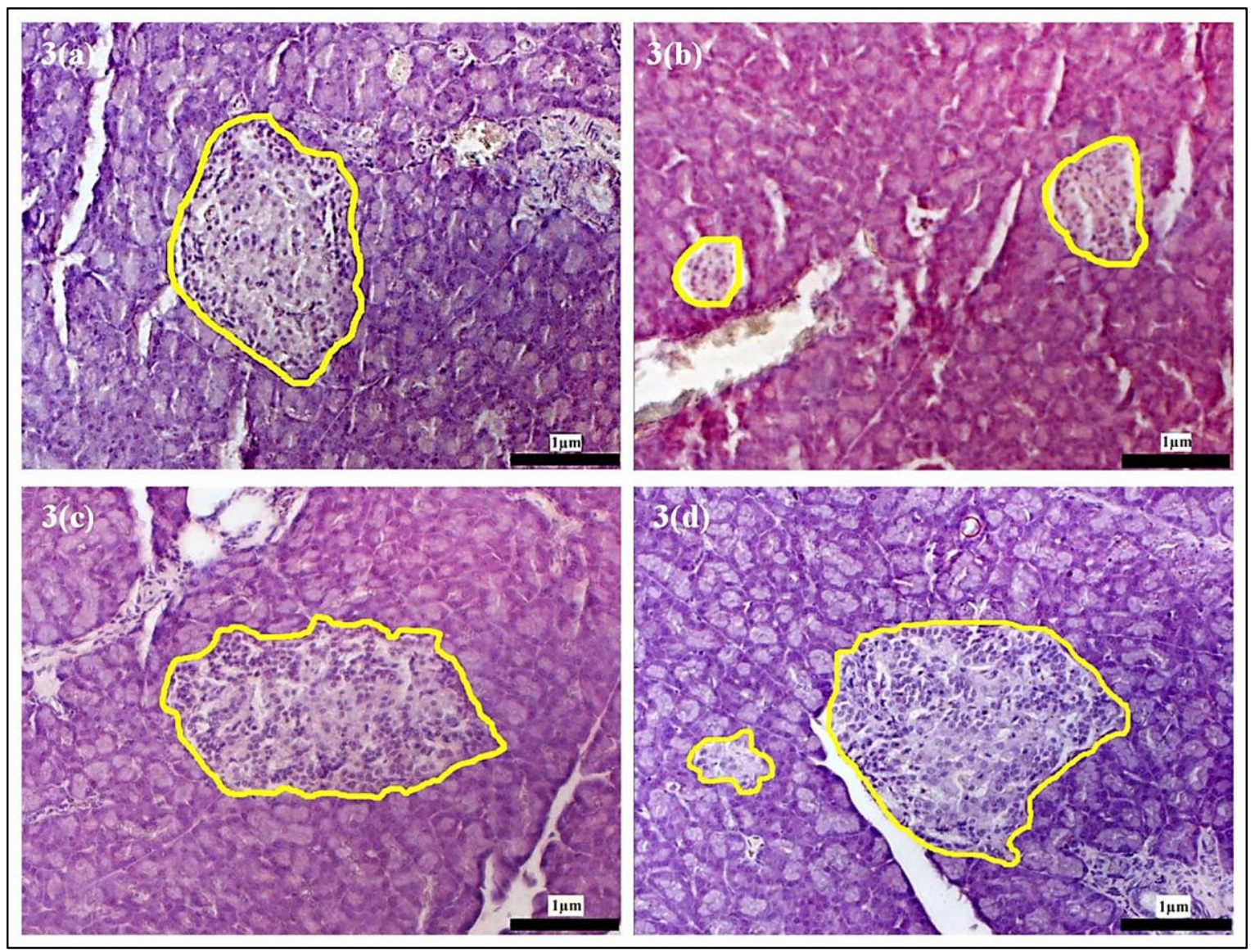

Figure 3. Islet morphology of rat pancreas at week 4 following treatment with A. borneensis extract. Tissue sections were obtained from (a) the normal control, (b) alloxan-only control, (c) $250 \mathrm{mg} / \mathrm{kg}$ b.w. dose treatment and (d) $500 \mathrm{mg} / \mathrm{kg} \mathrm{b.w.} \mathrm{dose} \mathrm{treatment} \mathrm{group.} \mathrm{The} \mathrm{pancreatic}$ islets are outlined in yellow (magnification 200x). 
The IPGTT blood glucose level of animals in the low dose-treated protective group continued to increase until 30 minutes post-blood glucose administration during which the blood glucose level peaked, followed by a gradual decline in the blood glucose level thereafter (Figure 1).

\subsection{Evaluation of islet morphology and morphometry}

Evaluation of the islet morphology of animals in alloxan-only control group showed presence of damaged islets where tissue sections taken from these animals at 72 hours post-alloxan injection showed severe atrophy and destruction in both endocrine and exocrine tissues (Figure 2). The size of the islets were significantly reduced as they appeared shrunken and the islets were difficult to identify as they showed a loss of integrity indicating damaged islets ${ }^{11}$. The islet cells have also displayed abnormal appearance where the cells appeared compressed and constricted (Figure 2). In agreement with the findings of Radenković et al. (2016), we observed that alloxan has exerted substantial damage to the islets of the animals within the first 72 hours of administration $^{12}$

Treatment with A. borneensis (either 250 or $500 \mathrm{mg} / \mathrm{kg}$ b.w.) resulted in apparent recovery of islets structure and size in the animals at weeks 4,8 and 12 of treatment (Figure 3, Figure 4 and Figure 5). The recovery of islet shape and ultrastructure was evident in the animals as early as week 4 following treatment with the plant extract, where majority of the islets appeared larger and were round- or oval-shaped (Figure 3). Interestingly, the pancreatic tissues of animals treated with A. borneeensis extract showed islet-like cell clusters emerging from the pancreatic duct, possibly contributing to expansion of the islets. Clusters of small rounded islets were also observed to be present in the pancreatic tissue of animals treated with $500 \mathrm{mg} / \mathrm{kg}$ b.w. of the A. borneensis extract.

\subsection{Ratio of islet size to tissue area}

The resulting ratio of islet size to tissue area for animals in the control, treatment and protective groups are shown in Table 2. The alloxan-induced animals treated with both 250 and $500 \mathrm{mg} / \mathrm{kg}$ b.w. of the $A$. borneensis extract showed a significant increase $(p<0.05)$ in islet to tissue ratio following the 12-week treatment period. Moreover, the ratios at 4,8 and 12 weeks following treatment with both doses of the $A$. borneensis extract were significantly higher $(p<0.05)$ than those of the alloxan-only control group (Table 2). In line with the increase in islet to tissue ratio, the islets might have simultaneously recovered some function as demonstrated by the reduction in blood glucose concentrations observed in both the low and high-dose treatment groups.

The ratio of islet size to tissue area of the animals in the protective group was also higher compared to the alloxan-only control group at 72 hours post-alloxan administration, although slightly lower than that of the animals in the normal control group. The higher islet size to tissue area ratios of animals from the protective group might have also resulted in the recovery of blood glucose levels for the animals when compared to those in the alloxan-only control group (Table 1).

Based on our findings, A. borneensis extract facilitates islet regeneration and protection, especially following an increase in demand for $\beta$-cell compensation in response to $\beta$-cell ablation by alloxan. However, its regenerative effect might be countered when the loss of $\beta$-cell mass is compensated, as demonstrated by the comparable ratio between the treatment and normal control group for week 12 (Table 2). The islets of animals treated with the $A$. borneensis extract also resumed full function as indicated by the normalized blood glucose concentration (Table 1) and glucose clearance (IPGTT) (Figure 1) at the end of the treatment period.

\section{DISCUSSION}

Alloxan-induced diabetic animals typically exhibit persistent long-term hyperglycaemia resulting from $\beta$-cell damage as observed in this present study. Our results showed that treatment of these diabetic animals with either 250 or $500 \mathrm{mg} / \mathrm{kg} \mathrm{b.w}$. of the $A$. borneensis extract significantly reduced blood glucose concentration, with more pronounced effect observed in the high dose treatment group during the first 8 weeks of treatment (Table 1). The blood glucose concentration in animals from the low and high dose groups were comparable from week 8 onwards and progressively improved by the end of the treatment period suggesting that $A$. borneensis extract contributed to the recovery from hyperglycaemia and restoration of normal glucose homeostasis.

The blood glucose reducing mechanism of the A. borneensis extract is still poorly understood to date. However, previous studies have attributed the antidiabetic effect of other plant extracts to the presence of well-known classes of phytochemical compounds such as alkaloids, flavonoids, polyphenols, carboxylic acid derivatives, glycosides and saponins ${ }^{13-14}$. Phytochemical screening conducted on the A. borneensis methanolic leaf extract revealed presence of a number of compounds including quinic acid (a polyphenolic compound) which was reported as the main constituent of the extract ${ }^{6,8}$. The antidiabetic activity of quinic acid has not been extensively studied, however Arya and colleagues (2014) have reported that administration of quinic acid significantly reduced blood glucose concentration, increased insulin levels and reduced lipid peroxidation 
in diabetic animals ${ }^{9}$. In addition to quinic acid, palmitic acid was also one of the phytochemical constituents detected in the A. borneensis leaf extract. Previous studies reported that palmitic acid and its derivatives could increase insulin sensitivity in peripheral tissues and have thus substantially improved glucose clearance in diabetic animals ${ }^{15}$. This finding complements our IPGTT data which showed that treatment with the $A$. borneensis extract resulted in relatively low blood glucose concentration over 120 minutes post-glucose administration in the alloxan-induced animals (Figure 1). These results suggest that the A. borneensis leaf extract has the potential capacity to control postprandial glucose concentration and improve glucose clearance, possibly via enhanced $\beta$-cell function and increased insulin sensitivity in the insulin target tissue.

A similar blood glucose lowering effect was observed in the protective animal group that received a 5-week pre-treatment with the A. borneensis extract prior to alloxan administration. The animals pre-treated with the low dose of $A$. borneensis extract was able to retain their blood glucose concentration at a moderate diabetic level of $14.70 \pm 3.38 \mathrm{mmol} / \mathrm{L}$ at 72 hours postalloxan administration (Table 1). This was supported by our IPGTT data, which showed that pre-treated animals from the protective group that subsequently received alloxan administration exhibited modest glucose clearance over the experimental period of 120 minutes after intraperitoneal injection with glucose (Figure 1). We also observed the general trend of increased water intake for animals in both the alloxan treated diabetic group and also protective group.

The glucose clearance and restoration of normal glucose homeostasis in the A. borneensis-treated animals was found to occur in parallel to the recovery of their pancreatic islets. In the present study, treatment with either the low or high dose of the A. borneensis extract facilitated regeneration of pancreatic islets within the first 4 weeks following extract treatment (Figure 3). The enhanced regeneration of pancreatic islets was not observed in the alloxan-only control animals (Figure 3). Further evaluation of islets following 8 and 12 weeks of treatment showed that the ratio of islet to tissue area of the animals in the A. borneensis extract-treated groups continued to increase until they were stabilized at a ratio of approximately 6:1 (Table 2).

In this study, we also detected the presence of small islet clusters in the pancreatic islets of the diabetic animals following 4 weeks of high dose treatment with the extract (Figure 3 ). This could represent newly formed islets born during the regenerative period following extract administration, which could later on, merge to form larger islets (Figure 4 and Figure 5). We also observed islet-like cell clusters emerging from the pancreatic ducts in the tissue sections of animals treated with the A. borneensis extract.

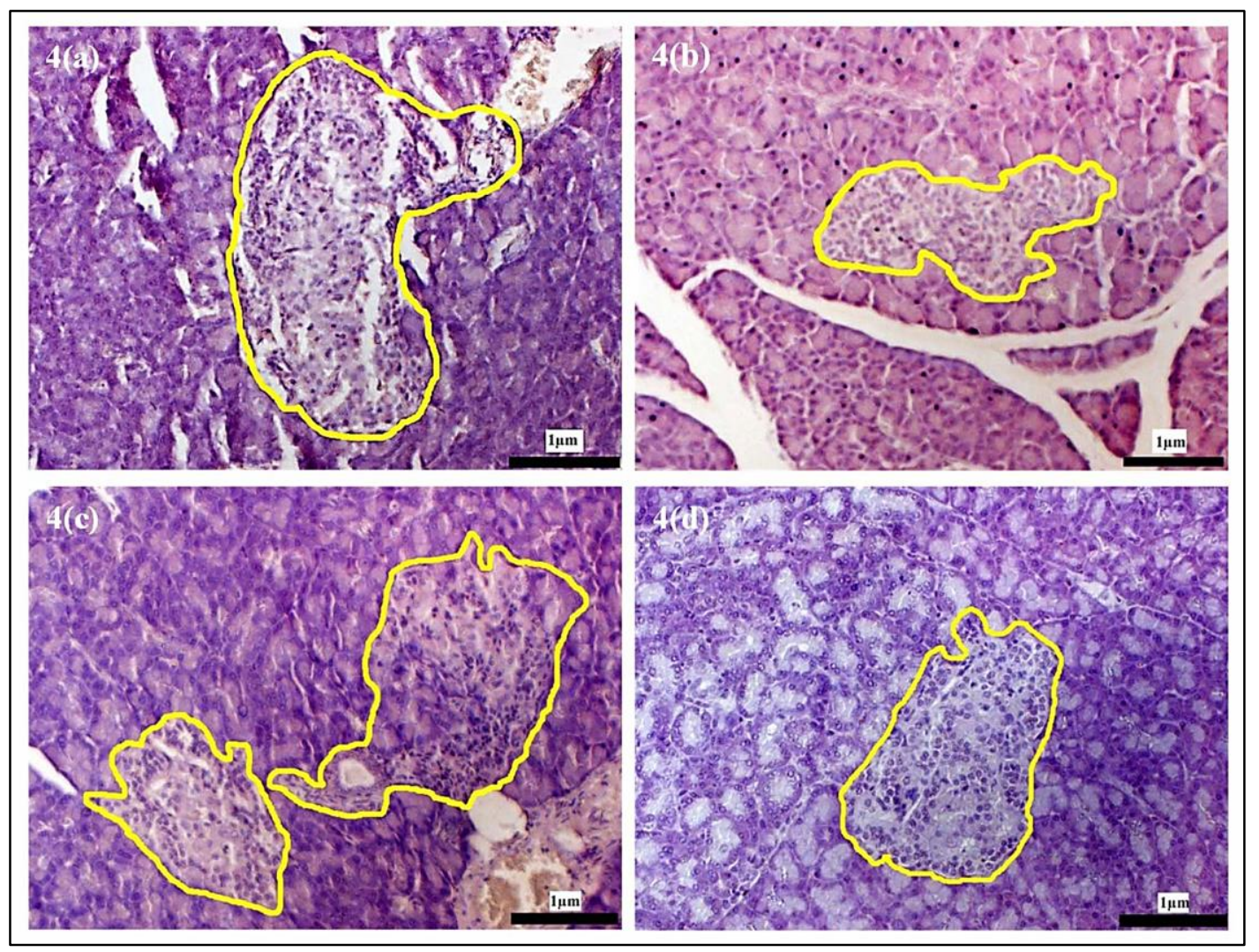

Figure 4. Islet morphology of rat pancreas at week 8 following treatment with A. borneensis extract. Tissue sections were obtained from (a) the normal control, (b) alloxan-only control, (c) $250 \mathrm{mg} / \mathrm{kg}$ b.w. dose treatment and (d) $500 \mathrm{mg} / \mathrm{kg}$ b.w. dose treatment group. The pancreatic islets are outlined in yellow (magnification 200x). 


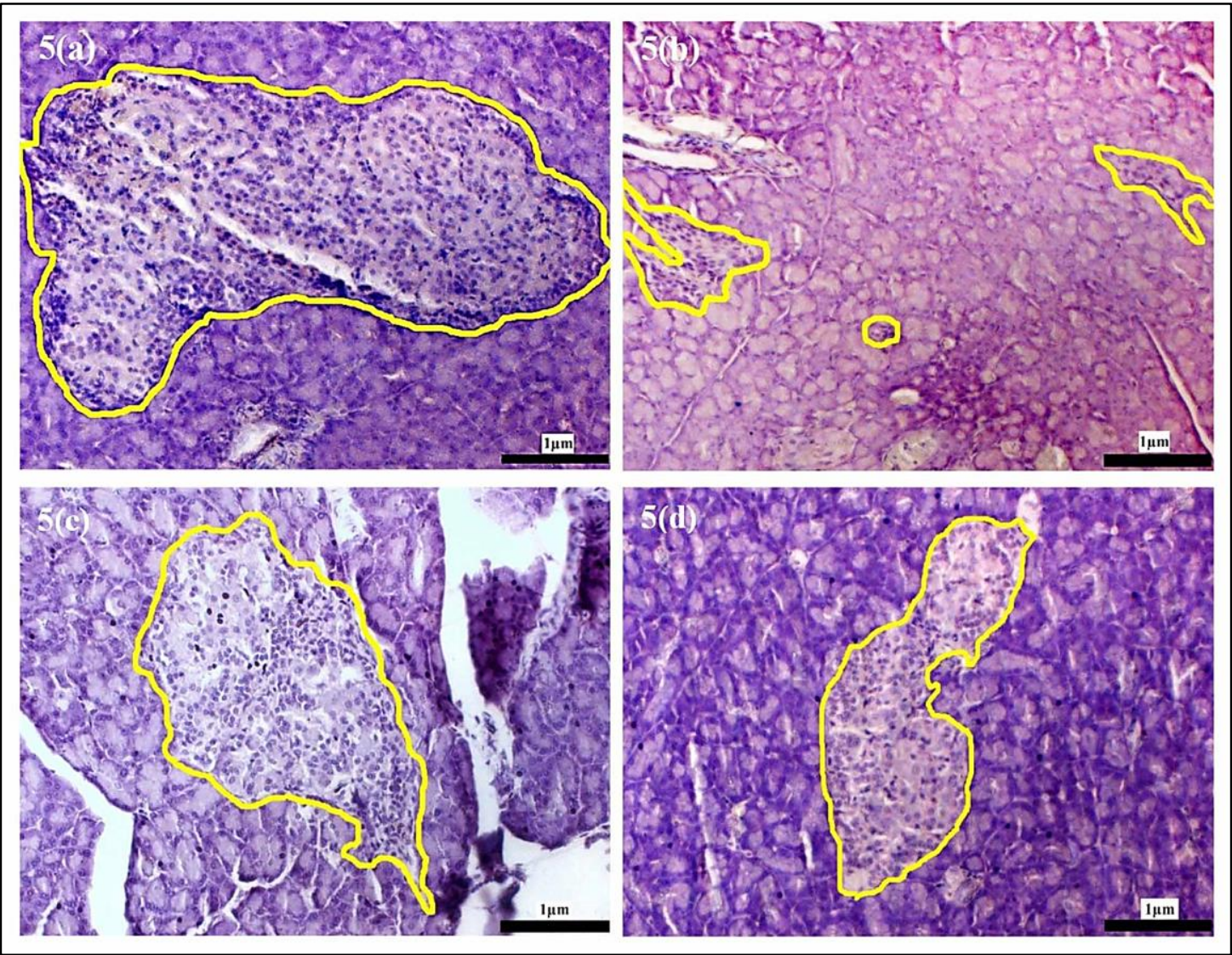

Figure 5. Islet morphology of rat pancreas at week 12 following treatment with $A$. borneensis extract. Tissue sections were obtained from (a) the normal control, (b) alloxan-only control, (c) $250 \mathrm{mg} / \mathrm{kg}$ b.w. dose treatment and (d) $500 \mathrm{mg} / \mathrm{kg}$ b.w. dose treatment group. The pancreatic islets are outlined in yellow (magnification 200x).

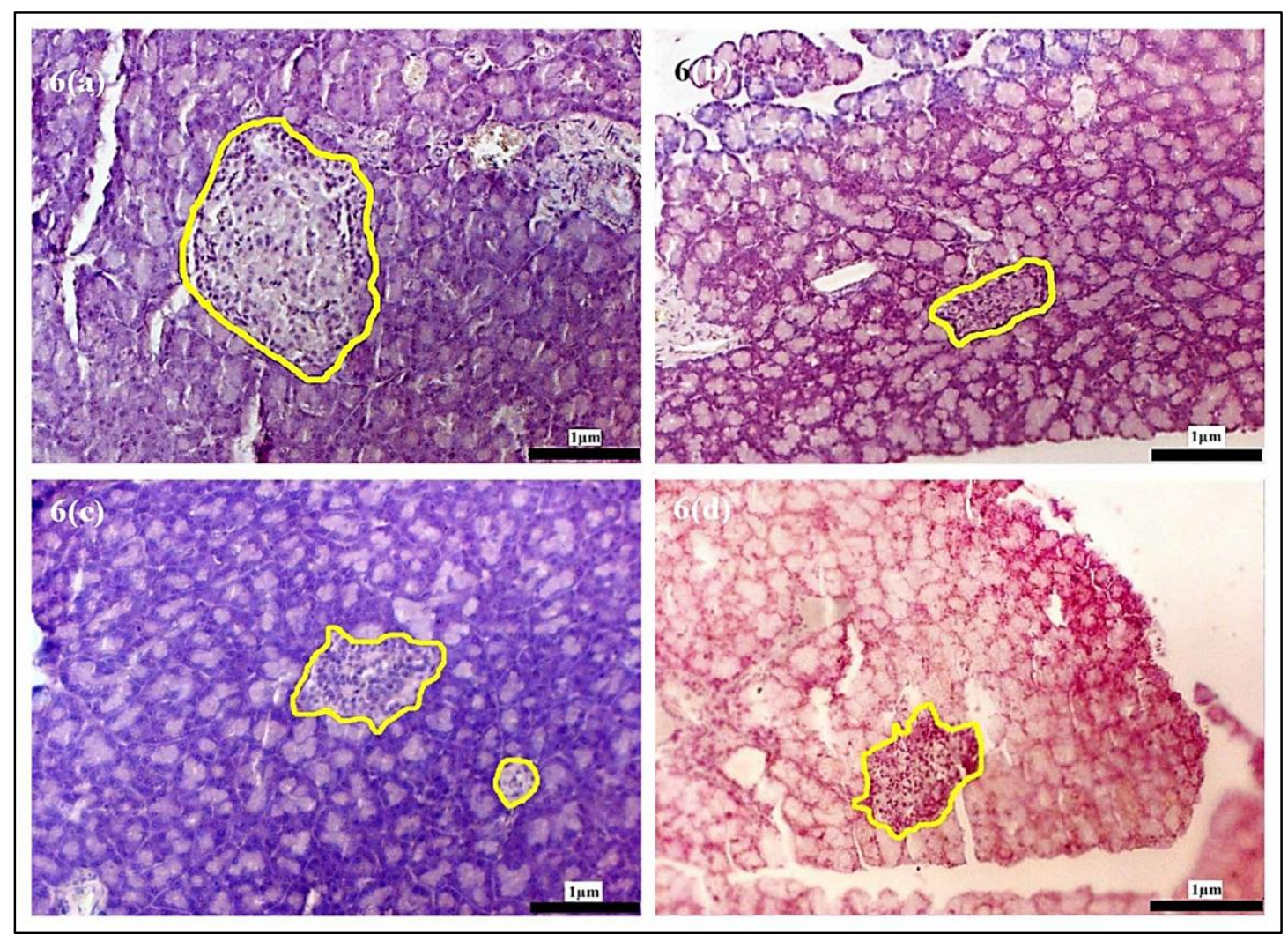

Figure 6. Pancreatic islet morphology of alloxan-treated rats 72 hours following pre-treatment with A. borneensis extract. Tissue sections were obtained from (a) the normal control, (b) alloxan-only control, (c) $250 \mathrm{mg} / \mathrm{kg}$ b.w. dose treatment and (d) $500 \mathrm{mg} / \mathrm{kg}$ b.w. dose treatment group. The pancreatic islets are outlined in yellow (magnification 200x). 
Similarly, the same cell types were also observed in the protective animal groups (Figure 6). These findings correlated with several previous studies which also showed the presence of similar islet-like clusters surrounding the pancreatic ducts during the regeneration period ${ }^{16-18}$. Xu et al. (2008) suggested that these new islet clusters could emerged from the proliferation of small amounts of $\beta$-cells that survived the $\beta$-cell ablation ${ }^{17}$. We speculated that the A. borneensis extract might have the potential to stimulate replication of the existing $\beta$-cells for islet expansion and regeneration in the pancreas of the alloxan-induced animals. The extract might also trigger signalling pathways that could trigger islet cells regeneration from non-islet cells residing in the pancreatic ducts following damage of the $\beta$-cells ${ }^{17}$.

The protection of pancreatic islets and $\beta$-cells was also observed in the animals from the protective groups as shown by preservation of islet morphology in the animals despite the size reduction observed in most islets for both the low and high dose pre-treated groups (Figure 6). The reduced islet size led to lower islet to tissue area ratios for the pre-treated animals compared to that of the normal control group (Table 2). Klimnik et al. (2012) and Zhang et al. (2009) reported in their studies that a decrease in islet areas indicated less $\beta$-cell availability and thus resulting in insufficient insulin production to maintain normal blood glucose homeostasis $^{19-20}$. In contrast to the reports above, results from the present study showed that pre-treatment of animals with the A. borneensis extract resulted in near-normal blood glucose levels in the animals, despite having low ratios of islet size to tissue area. Due to the histological sampling approach carried out, there might be some limitations to the outcomes of our counts where the sampled area might contain more or lesser islets. In light of the current study, understanding of the molecular mechanisms that interplays during the recovery process of the beta cells could provide some explanation on the mechanism of action of the plant extract. As our study involves the use of crude extracts from the plant, future studies will be directed towards the elucidation of the components within the crude extracts that bring about this effect. Further studies to determine the presence of insulin-producing cells in these islets will provide further insight on the blood glucose lowering mechanism of the A. borneensis extract.

\section{CONCLUSIONS}

Based on this current study, A. borneensis extract showed the potential to lower blood glucose concentration in diabetic animals, possibly via expansion of the pancreatic islet and function recovery as seen from the increased islet to tissue area ratios over the different recovery periods following alloxan ablation.
Furthermore, pre-treatment with the A. borneensis extract provided protection against hyperglycaemia and islet damage as observed in the animals from the protective groups. Further studies will need to be conducted such as phytochemical evaluation and toxicity studies in order to elucidate the mechanism of action of the extract prior to its use for antidiabetic purposes.

\section{ACKNOWLEDGEMENT}

This study was funded by Institute for Biodiversity and Environmental Research, Universiti Brunei Darussalam research grant (ref no: UBD/RSCH/1.13/ FICBF(b)/2020/021).

\section{Conflict of interest}

The authors declare that there is no conflict of interest.

\section{Funding}

This study was funded by Institute for Biodiversity and Environmental Research, Universiti Brunei Darussalam research grant (ref no: UBD/RSCH/1.13/ $\mathrm{FICBF}(\mathrm{b}) / 2020 /$ 021).

\section{Ethics approval}

The animal work in the current study has been approved by the University Research Ethics Committee of Universiti Brunei Darussalam (approval reference: UBD/ FOS/M2).

\section{Article info:}

Received March 27, 2021

Received in revised form May 12, 2021

Accepted May 12, 2021

\section{REFERENCES}

1. Surya S, Salam AD, Tomy DV, Carla B, Kumar RA, Sunil C. Diabetes mellitus and medicinal plants-a review. Asian Pac J Trop Dis. 2014;4(5):337-47.

2. Rahman IHA, Bakar JA, Metussin PHRPH, Mumin PHMPHA. An overview of functional foods of Brunei Darussalam. Scientia Bruneiana. 2006;2006:9-20.

3. Goh MPY, Basri AM, Yasin H, Taha H, Ahmad N. Ethnobotanical review and pharmacological properties of selected medicinal plants in Brunei Darussalam: Litsea elliptica, Dillenia suffruticosa, Dillenia excelsa, Aidia racemosa, Vitex pinnata and Senna alata. Asian Pac J Trop Biomed. 2017;7(2):173-80.

4. Department of Agriculture. Medicinal Plants of Brunei Darussalam. Revised ed. Brunei Darussalam: Ministry of Industry and Primary Resources; 2000.

5. Awang-Jamil Z, Basri A, Ahmad N, Taha H. Phytochemical analysis, antimicrobial and antioxidant activities of Aidia borneensis leaf extracts. J Appl Biol Biotechnol. 2019;7(5):92-7.

6. Metussin NB, Mohamed HJ, Ahmad N, Yasin HM, Usman A. Evaluation of antioxidant capacity of Aidia borneensis leaf infusion, an endemic plant in Brunei Darussalam. Food Research. 2017;2:12-9.

7. Awang-Jamil Z. Chemical compositions and antimicrobial activities of plant extracts from the leaves of Aidia Raccemosa 
and Merremia borneensis. B. Sc. [dissertation]. Brunei Darussalam: Faculty of Science, University of Brunei Darussalam; 2012.

8. Arya A, Jamil M, Shahid N, Noordin MI, Looi CY, Wong WF, et al. Synergistic effect of quercetin and quinic acid by alleviating structural degeneration in the liver, kidney and pancreas tissues of STZ-induced diabetic rats: A mechanistic study. Food Chem Toxicol. 2014;71:183-96.

9. Matusin AH, Abd Ghani NI, Ahmad N. Pancreatic islet regenerative capability of Dillenia excelsa in alloxan-induced diabetic rats. J Appl Pharm Sci. 2021;11(3):121-9.

10. Qinna N, Badwan A. Impact of streptozotocin on altering normal glucose homeostasis during insulin testing in diabetic rats compared to normoglycemic rats. Drug Des Devel Ther. 2015; 9:2515-25.

11. Cheekati RR, Rao AS, Vijayaraghavan R. A histological study of alloxan-induced diabetes on experimental male Wistar rats. Natl J Physiol Pharm Pharmacol. 2017;7(12):1329-34.

12. Radenković M, Stojanović M, Prostran M. Experimental diabetes induced by alloxan and streptozotocin: The current state of the art. J Pharmacol Toxicol Methods. 2016;78:13-31.

13. Abdelrazek H, Kilany OE, Muhammad M, Tag HM, Abdelazim AM. Black seed thymoquinone improved insulin secretion, hepatic glycogen storage, and oxidative stress in streptozotocin- induced diabetic male wistar rats. Oxid Med Cell Longev. 2018; 2018:1-10.

14. Tan M, Ye J, Turner N, Hohnen-Behrens C, Ke C, Tang C, et al. Antidiabetic activities of triterpenoids isolated from bitter melon associated with activation of the ampk pathway. Chem Biol. 2008; 15:263-73.

15. Santoro A, Zhou P, Peroni O, Syed I, Nelson A, Siegel D, et al. Palmitic acid esters of hydroxy stearic acids are hepatic insulin sensitizers in chow and high-fat diet (hfd)-fed mice. Diabetes. 2018;67(Supplement1):1838-P.

16. Aguayo-Mazzucato C, Bonner-Weir S. Pancreatic $\beta$ cell regeneration as a possible therapy for diabetes. Cell Metab. 2018;27(1): 57-67.

17. Xu X, D’Hoker J, Stangé G, Bonné S, De Leu N, Xiao X, et al. $\beta$ cells can be generated from endogenous progenitors in injured adult mouse pancreas. Cell. 2008;132:197-207.

18. Zhou Q, Melton DA. Pancreas regeneration. Nature. 2018; 557(7705):351-8

19. Kilimnik G, Jo J, Periwal V, Zielinski MC, Hara M. Quantification of islet size and architecture. Islets. 2012;4(2):167-72.

20. Zhang Z, Jiang J, Yu P, Zeng X, Larrick JW, Wang Y. Hypoglycaemic and beta cell protective effects of andrographolide analogue for diabetes treatment. J Transl Med. 2009; 7:62. 